\title{
Automated Flow Cytometry: An Alternative to Urine Culture in a Routine Clinical Microbiology Laboratory?
}

\author{
Patricia Mejuto, ${ }^{1}$ Mariam Luengo, ${ }^{2}$ and Julio Díaz-Gigante ${ }^{1}$ \\ ${ }^{1}$ Department of Microbiology, Hospital del Oriente de Asturias Francisco Grande Covián, Arriondas, Asturias, Spain \\ ${ }^{2}$ Department of Biochemistry, Hospital del Oriente de Asturias Francisco Grande Covián, Arriondas, Asturias, Spain \\ Correspondence should be addressed to Patricia Mejuto; patriciamejutolv@gmail.com
}

Received 11 July 2017; Accepted 22 August 2017; Published 27 September 2017

Academic Editor: Maurizio Sanguinetti

Copyright (c) 2017 Patricia Mejuto et al. This is an open access article distributed under the Creative Commons Attribution License, which permits unrestricted use, distribution, and reproduction in any medium, provided the original work is properly cited.

\begin{abstract}
The urine culture is the "gold standard" for the diagnosis of urinary tract infections (UTI) but constitutes a significant workload in the routine clinical laboratory. Due to the high percentage of negative results, there is a need for an efficient screening method, with a high negative predictive value (NPV) that could reduce the number of unnecessary culture tests. With the purpose of improving the efficiency of laboratory work, several methods for screening out the culture-negative samples have been developed, but none of them has shown adequate sensitivity (SE) and high NPV. Many authors show data about the efficacy of flow cytometry in the routine clinical laboratory. The aim of this article is to review and discuss the current literature on the feasibility of urine flow cytometry (UFC) and its utility as an alternative analytical technique in urinalysis.
\end{abstract}

\section{Introduction}

Urinary tract infections (UTIs) are among the most common infections in both hospitalized patients and outpatients [1$4]$, and the health cost they cause is considerable. About $50 \%$ of women state that they have experienced one infection in their lifetime and $27-48 \%$ of them have recurrent infections [5], mainly in senior women living in the community [6]. Although for most patients the disease of the infection is minimal, in certain population groups like children, pregnant women, the elderly, and immunosuppressed patients, it is associated with severe complications [7]. In the USA, it is responsible for more than 7 million medical visits annually, and the most recent medical literature indicates a global prevalence of $0.7 \%$ of community-acquired UTI (19.6\% in Europe, $12.9 \%$ in the USA, and $24 \%$ in developing countries) [8]. According to medical literature, E. coli more usually causes lower community-acquired UTI $[9,10]$. Up to $15 \%$ of antibiotics prescribed in the community are due to these infections, with an annual cost of approximately 1.6 billion US dollars [11]. Taking these data into account, there is an enhanced risk of antibiotic resistance [12].

The diagnosis of UTI is based on clinical signs and symptoms of the patient and urinalysis results. Consequently, urine samples are the most numerous specimens received by clinical microbiology laboratories. Culturing of the urine samples is the "gold standard" method to exclude these infections, although it is a significant workload and timeconsuming in the microbiology laboratory [13]. Nevertheless, a high percentage of these specimens will yield no growth, reaching even up to $60 \%$ of negative results $[14,15]$. Also, other different urinalysis techniques are widely used in routine laboratories. The dipstick chemical test is based on strips that had reagent pads for semiquantitative assessment of nitrite (a product of common urinary pathogens), leukocyte esterase, protein, and blood (as a sign of inflammation). This method has a poor NPV, which makes it unsuitable to exclude the presence of urine infection. It is only useful in populations when the results of both nitrite and leukocyte esterase are positive [16]. However, with a negative result, UTI cannot be excluded mainly in children, who normally have low bacterial counts [17]. Another technique is the microscopic examination of urine sediment where cells, particles, and microorganism are counted and reported according to the number observed. Diverse factors can produce interpretation errors, and there are different results among laboratories, due to interindividual variability [18]. Although these screening 
methods are primarily used in general practice and microbiology laboratories, they are subjective and time-consuming or have a poor sensitivity and/or specificity. For ten years ago, the use of flow cytometry analyzers (FCA) based on detection and quantification both leukocytes and bacteria have been under evaluation. These techniques would reduce the number of samples cultured with a sharp decrease in workload, time, and costs especially in the bigger clinical laboratories [19]. In this way, negative results could be informed considerably earlier, which would imply a reduction of unnecessary empirical antibiotic prescriptions [20].

\section{Review Methods}

Data from 2009 to 2017 were assessed. The search process was conducted using Cochrane, the electronic databases Pubmed/ NCBI, and Google Scholar. The terms "urine flow cytometer," "flow cytometry," "urinary tract infection," "screening urinary tract infection" and "flow cytometry analyzers" were used. We also searched reference lists of articles to identify supplementary information. Citations were limited to studies conducted in humans and using the UF1000i (Sysmex) analyzer for UTI screening and the urine culture as the reference standard. Conference abstracts were excluded due to lack of information provided. Our initial literature search yielded 605 unique citations. After a critical evaluation, based on study design, a total of 17 articles were selected, for review (Table 1).

\section{Diagnosis of Urinary Tract Infection}

The detection of the uropathogen by urine culture is the "gold standard" for the diagnosis of UTI. In this way, the level of the bacteriuria can be estimated and the antimicrobial susceptibility determined. However, the minimum number of bacteria demonstrating an infection of the urinary tract has not been specified in the scientific literature or fixed by microbiological laboratories [37, 38]. In 1960, Kass developed the concept of significant bacteriuria as more than $10^{5} \mathrm{CFU} / \mathrm{mL}$ when pyelonephritis happens during pregnancy [39]. This assessment introduced quantitative microbiology into the diagnosis of infectious diseases and is therefore still of general importance. But, there is no standardized bacterial count that indicates significant bacteriuria, applicable in all types of UTIs.

The European urinalysis guidelines recommend the following limits of uropathogens counts, for a diagnosis of UTI [36, 40]: a threshold of $>10^{5}$ Colony Forming Unit (CFU) per $\mathrm{ml}$ in $\mathrm{MSU}$ (midstream urine) in women or $>10^{4} \mathrm{CFU} / \mathrm{ml}$ in $\mathrm{MSU}$ in men or straight urine catheter in complicated UTI in women; more than $10^{4} \mathrm{CFU} / \mathrm{ml}$ in a MSU in uncomplicated pyelonephritis in women or $>10^{3} \mathrm{CFU} / \mathrm{ml}$ in MSU in uncomplicated cystitis in women. In a sample of urine obtained by bladder puncture, any count is significant. According to the Infectious Diseases Society of America (IDSA) guideline, for uncomplicated UTI, counts of more than $10^{4} \mathrm{CFU} / \mathrm{ml}$ can be considered as the cut-off for positive culture $[41,42]$.

\section{Urinary Flow Cytometer Principle}

Flow cytometer analyzers are systems for the rapid, optical analysis of individual cells that allow simultaneous analysis of chemical and/or physical characteristics of single urinary particles [43]. Measurement is made by an array of detectors as the cells flow in a fluid stream through a laser beam. The urinary flow cytometer (UFC) can identify red blood cells (RBC), white blood cells (WBC), squamous epithelial cells, small round cells (renal tubular cells and transitional epithelial cells), hyaline casts, bacteria, yeast-like cells, spermatozoa, and crystals. The urine sample is automatically mixed, aspired, and stained using a specific fluorescent polymethine dye in two different analytical chambers: one for bacteria and another one for other urine forming elements. Once stained, the fluorescent particles are inserted into the cytometer pool and exposed to the semiconductor laser beam $(\lambda 635 \mathrm{~nm})$. For each particle the scattered light is detected at two positions: forward and side scatters and fluorescence intensities are produced $[44,45]$. These signals are converted to optoelectronic signals so that components can be identified, counted, classified, and analyzed. Bacteria are counted via an individual bacterial examination channel, so any interference with RBCs is prevented. All the results are presented in histograms and scattergrams by the software. Each particle type is color coded for the ease of reading. The bacteria and WBC counts are recorded in a database for subsequent analysis to determine the optimal screening method.

In recent years, the analytical quality of these analyzers has been improved because bacteria are counted in an independent examination channel, and interference with red blood cells is prevented. Also, the latest models have a more powerful laser that provides a high sensitivity analytic as well as a flag which informs on the gram characteristics of bacteria detected.

\section{Studies}

Several studies reported different sensitivities and specificities about the application of flow cytometry in the diagnosis of suspected UTI. The results obtained depend on the definition used for gold standard positive and negative urines cultures, and these definitions vary among laboratories. For example, most often $>10^{5} \mathrm{CFU} / \mathrm{ml}[22,25,27,29,46]$ has been considered a threshold for positive urine cultures in the clinical, microbiological practice. Some authors used pathogenicity cut-offs of $10^{3} \mathrm{CFU} / \mathrm{ml}$ or less $[28,47,48]$ while others consider high counts of $10^{5} \mathrm{CFU} / \mathrm{ml}$ that were still measured negative [49]. Taking into account these microbial counts limits, authors establish different cut-off values of bacteria and leukocytes per $\mu \mathrm{l}$, below which the reported result of the urinalysis will be negative. We have observed that when increasing the definition of a negative urine culture, the cut-points that the authors use for screening are higher. In the same way, these combinations of cutoff values might improve the combination of sensitivity and specificity of detecting UTI by the analyzer. For example, Broeren et al. [14] reported a SE of $96 \%$, a SP $78 \%$, and a NPV of $99.7 \%$, at a cutoff value of 230 bacteria/ $\mu \mathrm{l}$, when a definition of negative urine culture 


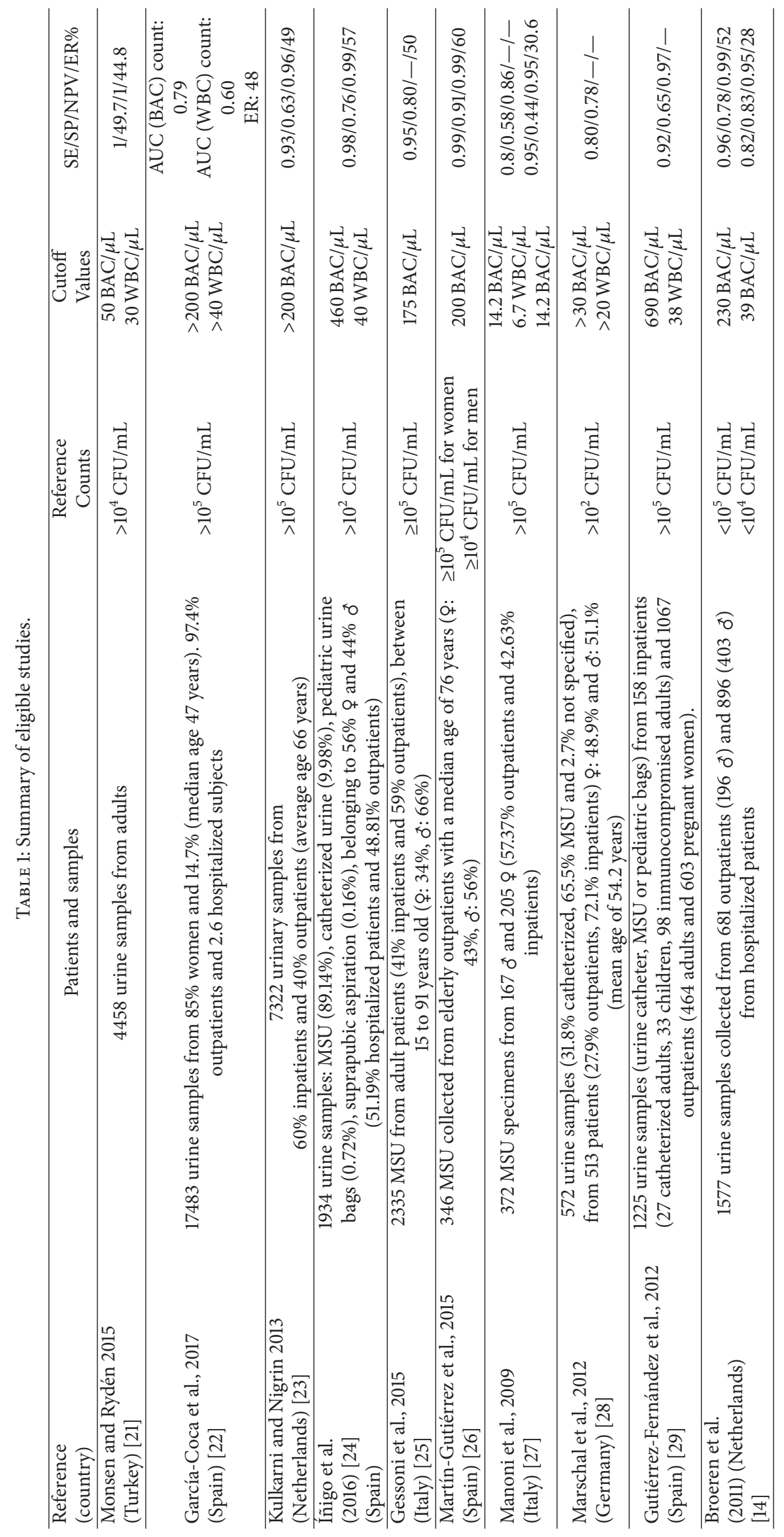




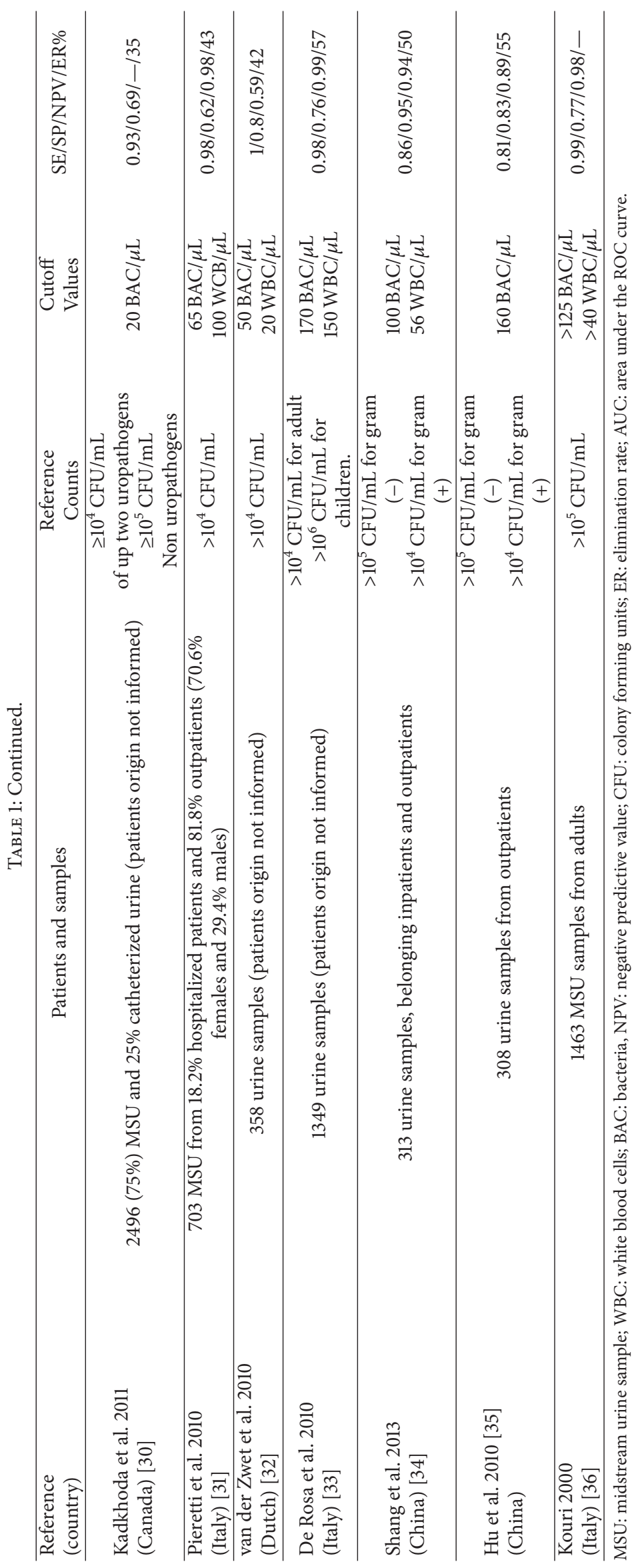


of $<10^{5} \mathrm{CFU} / \mathrm{ml}$ was used. When these authors choose a less stringent gold standard definition $\left(<10^{4} \mathrm{CFU} / \mathrm{ml}\right)$, the cutoff decreases until 39 bacteria/ $\mu$ l, with a consequent decrease in SE $(82 \%)$ and an increase of SP (83\%). Other studies, with the same definition of negative urine culture $\left(<10^{5} \mathrm{CFU} / \mathrm{ml}\right)$, show different data. Manoni et al. [27] choose cut-off values for bacteria and leukocytes of $125 / \mu \mathrm{l}$ and $40 / \mu \mathrm{l}$, respectively, to obtain a sensibility of $97 \%$ with a specificity of $94 \%$. Gutiérrez-Fernández et al. [29] fix different counts limits (690 bacteria/ $\mu \mathrm{l}$ and 38 leukocytes/ $\mu \mathrm{l})$, mainly due to differences in the population analyzed.

On the other hand, in two studies, we observed strikingly low cut-off points. Kadkhoda et al. [30] considered $>20$ bacteria/ $\mu$ l, using a definition of culture positive of $>10^{5} \mathrm{CFU} / \mathrm{ml}$ for uropathogens. Krongvoraluk et al. [50] showed the lowest cutoffs of the revised literature (bacteria $>14.2 / \mu \mathrm{l}$ and leukocyte $>6.7 / \mu \mathrm{l})$, perhaps for the use of the filter paper method instead of the calibrated loop urine quantification technique.

Diverse papers have shown that the use of FCA reduces the number of processed negative urinary specimens. Authors demonstrate variably reduction in bacterial culture ranging from $28 \%$ to $60 \%$ [14, 22, 24-26, 29-33, 50]

We observed a wide variation in cut-off points applied, as well as in the SE and SP of the results obtained in the literature. Several authors did not recommend to use a standard, unique cutoff value of both bacteria and leukocytes counts. These will be chosen depending on the characteristics of the analyzed population, which is usually heterogeneous. Furthermore, published data recommended adjusting the cutoff values according to gender and age of the patients to increase detection reliability $[15,23,31,51]$.

If confirmed in studies with larges series, the UFC screening method would be more efficient when both bacterial and leukocyte counts were detected. Various authors demonstrate that this implies an increase in the sensitivity of the technique $[24,29,33,35,49]$. In contrast to these findings, other studies do show no benefit when combining the use of both counts for UTI screening [14, 26, 30].

Also, some authors suggest that, with the general definition of $<10^{5} \mathrm{CFU} / \mathrm{ml}$ for a negative urine culture, a significant amount of microorganisms would not be considered. But, down CFU counts $\left(\leq 10^{3} \mathrm{CFU} / \mathrm{ml}\right)$ in some specific groups of patients (urological patients, children, pregnant women, and catheterized patients or when "fastidious" microorganisms are involved) are relevant. For this reason, some authors suggest that these samples have to be evaluated individually and also cultivated $[14,27,30]$.

On the other hand, diverse studies with similar patient population analyzed, and the same gold standard definition for negative culture, show differences in the number of false negative results $[14,27,33]$. Diverse aspects can explain these discrepancies. Defects in the cytometer detection of Grampositive bacteria, due to phenomena of aggregation, have been described by several authors $[47,49,52]$. There are other factors than can lead to high count false negatives: antibiotic treatment before urine analysis, for nonviable bacteria detection [14] as well as different culture procedures, transportation times or the use of boric acid as preservative [19].
We checked that the majority of subjects analyzed were outpatients $[14,22,26,29,31,35]$, whereas other authors evaluated mainly samples of hospitalized patients [28, 53]. Besides, most studies did not establish the discrepancies between hospitalized patients and outpatients. But, it is important to distinguish them because there are substantial differences, in connection with the presence of catheters or the use of antimicrobials [19].

Concerning to microorganisms causing UTI, Gramnegative bacteria were reported more frequently, being $E$. coli the most prevalent microorganism isolated in samples with significant bacteriuria. In different series analyzed, it represents more than $50 \%$ of isolates [27, 30, 33, 52]. Curiously, Monsen and Rydén [21] confirmed that different microorganisms were associated with distinct parameters counts. Proteus mirabilis, P. aeruginosa, S. aureus, and group C streptococci showed high leukocyte counts. Klebsiella sp. had smaller leukocyte counts whereas the highest bacterial, leukocyte, and erythrocyte counts were found for E. coli. One study conducted in Spain [22] demonstrated that cultures with E. coli and Klebsiella spp. had less epithelial cells counts that contaminated urine samples. And specimens with Enterococcus spp. were associated with lower WBC counts than negative urines.

From an economical point of view, some studies have examined the possible savings that would be obtained with the use of this automated system in routine clinical microbiology laboratories. Marschal et al. [28] demonstrated money savings of 5965 euros every 12000 urine samples per year. And in one study conducted in Turkey, Yasuma et al. [54] showed savings of 239-306 US dollars per 100 samples. Ilki et al. confirmed that the method is cost efficient since it represents savings of at least 6798 euros [55].

Finally, in most of the eligible studies it was unknown if patient's clinical manifestations were representatives of UTI. On the other hand, criteria of inclusion and exclusion were not determined as well as information about preanalytical phase. Also, only a few studies reported the percentage of contaminated samples and its influence in UTI prevalence.

\section{Conclusions}

It is not possible to provide effective patient management if the results of urinary investigation are not interpreted considering patient's clinical characteristics. It is important to remember that the number of bacteria deemed relevant for the diagnosis of UTI depends on various factors. The type of specimen (mid-stream urine, bag urine, catheter urine, urostomy urine, and suprapubic aspiration urine), clinical situation of the patient (abnormalities of the genitourinary tract, presence of clinical manifestations, gender, age, pregnancy, and antibiotics previously taken), or variety of bacteria (category and isolated species) should be considered [19]. With a unique gold-standard definition for a negative culture of $<10^{5} \mathrm{UFC} / \mathrm{ml}$, the presence of high bacteria amount is considered not significant. That is questionable, especially for particular patients as well as children, pregnant women, and older adults, for whom low counts are relevant. 
Classical microbiology techniques are quite slow in comparison to new automated methods, based on advanced technologies for UTI screening, as they require the isolation of the organism before its identification and subsequently antibiotic susceptibility determination. With the implementation of FCA in clinical laboratories, the results are practically available in real time, within a few minutes of the sample admission and can be promptly informed in case of negative results.

It is vital to bear in mind that sensitivity is the most important requirement of a good screening process. In a screening test all positive specimens are cultured and, consequently, false-positive results will not be informed to the clinicians [27]. For FC to be a useful rapid test to rule out negative urine samples, the attention should be paid to obtaining the optimal results in comparison with the urine culture. This would require the highest sensibility and therefore a high negative predictive value, to minimize the number of false negative results.

Different limits for both leukocytes and bacteria detection were established in available reports. Each microbiology laboratory should adjust its bacteria and leukocytes cutoffs, depending on their UTI prevalence and the pathology of the patients analyzed as well as their origins, gender, and age.

In patients with UTI, the TAT (turnaround time) for a test result is approximately $48 \mathrm{~h}$. For a patient with overt clinical manifestations, it is too long, because the introduction of antibiotic therapy should be early. Unfortunately, the most active antibiotics against Gram-positive bacteria are not useful in Gram-negative germs, which are the most frequent bacteria involved in urinary tract infections. Differentiating the type of bacteria involved in these infections would help to improve the efficacy of empirical therapy [49, 56, 57]. If information about the Gram properties of the suspected bacteria was available quickly, clinicians could select the most effective antibiotic for UTI infection.

Most revised articles have agreed that FC is a useful method for screening urinary samples if the optimal cut-off value is established for each group of patients. The adoption of correct criteria is crucial to improving the performance of the screening process. This will lead to significant reduction in TAT of negative cultures in bacterial culture and unnecessary empirical antibiotic prescription. However, in subjects at risk of UTI complications, its use is controversial, being the culture necessary.

In the future, perhaps the possibility of combining these systems with a rapid identification technique like matrixassisted laser desorption ionization time-of-flight (MALDITOF) mass spectrometry (MS) can permit recognizing bacterial species directly in urine positive samples [58-60] and choosing the best antibiotics depending on the results provided by the analyzer. Further studies could be of interest to investigate the impact of these automatic techniques in both prescription of antibiotics and its relationship with patient care.

At present, there is a need to improve the quality and optimize the procedures performed in laboratories. Before deciding to automate a manual technique, a rigorous study should be conducted. In this way, microbiologists could offer the best diagnostic option to patients and physicians.

\section{Disclosure}

This research received no specific grant from any funding agency in the public, commercial, or not-for-profit sector

\section{Conflicts of Interest}

All authors declare that they have no conflicts of interest.

\section{Authors' Contributions}

Patricia Mejuto, Julio Díaz-Gigante, and Mariam Luengo participated in the planning of the study, wrote the first draft of the manuscript, revised it critically, and approved the final version.

\section{Acknowledgments}

The authors greatly appreciate the help received from Rosa F. Buisson for English language revision.

\section{References}

[1] K. G. Naber, "Urogenital infections: the pivotal role of the urologist," European Urology, vol. 50, no. 4, pp. 657-659, 2006.

[2] J. Santra, P. Eeva-Liisa, K. Pauliina, and et al., "Screening of urine samples by flow cytometry reduces the need for culture," Journal of Clinical Microbiology, vol. 48, no. 9, pp. 3117-3121, 2010.

[3] J. C. dos Santos, L. P. Weber, and L. R. R. Perez, "Evaluation of urinalysis parameters to predict urinary-tract infection," Brazilian Journal of Infectious Diseases, vol. 11, no. 5, pp. 479481, 2007.

[4] B. Foxman, "Urinary tract infection syndromes. Occurrence, recurrence, bacteriology, risk factors, and disease burden," Infectious Disease Clinics of North America, vol. 28, no. 1, pp. 1-13, 2014.

[5] T. M. Hooton, "Pathogenesis of urinary tract infections: an update," Journal of Antimicrobial Chemotherapy, vol. 46, S1, pp. $1-7,2000$.

[6] S. J. Matthews and J. W. Lancaster, "Urinary tract infections in the elderly population," American Journal Geriatric Pharmacotherapy, vol. 9, no. 5, pp. 286-309, 2011.

[7] B. Foxman, "Epidemiology of urinary tract infections: incidence, morbidity, and economic costs," The American Journal of Medicine, vol. 113, no. 1, pp. 5-13, 2002.

[8] Z. Tandogdu and F. M. Wagenlehner, "Global epidemiology of urinary tract infections," Current Opinion in Infectious Diseases, vol. 29, no. 1, pp. 73-79, 2016.

[9] J. P. Horcajada, E. Shaw, B. Padilla et al., "Healthcare-associated, community-acquired and hospital-acquired bacteraemic urinary tract infections in hospitalized patients: A prospective multicentre cohort study in the era of antimicrobial resistance," Clinical Microbiology and Infection, vol. 19, no. 10, pp. 962-968, 2013.

[10] ECDC 2012, Annual epidemiological report: reporting on 2010 surveillance data and 2011 epidemic intelligence data, European Centre for Disease Prevention and Control, Stockholm, Sweden, 2012, http://www.ecdc.europa.eu/en/publications/publications/ annual-epidemiological-report-2012.pdf. 
[11] K. G. Naber et al., EAU/International Consultation on Urological Infections, The Netherlands European Association of urology, 2010.

[12] A. Sorlozano, A. Jimenez-Pacheco, J. de Dios Luna del Castillo et al., "Evolution of the resistance to antibiotics of bacteria involved in urinary tract infections: a 7-year surveillance study," American Journal of Infection Control, vol. 42, no. 10, pp. 10331038, 2014.

[13] EM. Davies and DA. Lewis, "Bacteriology of urine," in Medical bacteriology Oxford, P. Hawkey and DA. Lewis, Eds., pp. 1-25, Oxford University Press, 2004.

[14] M. A. C. Broeren, S. Bahçeci, H. L. Vader, and N. L. A. Arents, "Screening for urinary tract infection with the sysmex UF-1000i urine flow cytometer," Journal of Clinical Microbiology, vol. 49, no. 3, pp. 1025-1029, 2011.

[15] S. Jolkkonen, E.-L. Paattiniemi, P. Kärpänoja, and H. Sarkkinen, "Screening of urine samples by flow cytometry reduces the need for culture," Journal of Clinical Microbiology, vol. 48, no. 9, pp. 3117-3121, 2010.

[16] R. E. Berger, "The urine dipstick test useful to rule out infections. A meta-analysis of the accuracy," The Journal of Urology, vol. 174, no. 3, pp. 941-942, 2005.

[17] Y. Waisman, E. Zerem, L. Amir, and M. Mimouni, "The validity of the uriscreen test for early detection of urinary tract infection in children.", Pediatrics, vol. 104, no. 4, p. e41, 1999.

[18] V. Wiwanitkit, N. Udomsantisuk, and C. Boonchalermvichian, "Diagnostic value and cost utility analysis for urine Gram stain and urine microscopic examination as screening tests for urinary tract infection," Urological Research, vol. 33, no. 3, pp. 220-222, 2005.

[19] S. Grosso, G. Bruschetta, and R. De Rosa, "Improving the efficiency and efficacy of pre-analytical and analytical workflow of urine cultures with urinary flow citometry," New Microbiol, vol. 31, pp. 501-505, 2008.

[20] W. J. Isaac, D. E. Low, A. Biringer, N. Pimlott, M. Evans, and R. Glazier, "The impact of empirical management of acute cystitis on unnecessary antibiotic use," Archives of Internal Medicine, vol. 162, no. 5, pp. 600-605, 2002.

[21] T. Monsen and P. Rydén, "Flow cytometry analysis using sysmex UF-1000i classifies uropathogens based on bacterial, leukocyte, and erythrocyte counts in urine specimens among patients with urinary tract infections," Journal of Clinical Microbiology, vol. 53, no. 2, pp. 539-545, 2015.

[22] M. García-Coca, I. Gadea, and J. Esteban, "Relationship between conventional culture and flow cytometry for the diagnosis of urinary tract infection," Journal of Microbiological Methods, vol. 137, pp. 14-18, 2017.

[23] S. Kulkarni and J. Nigrin, "Letter to the Editor re: "Performance of flow cytometry to screen urine for bacteria and white blood cells prior to urine culture"," Clinical Biochemistry, vol. 46, no. 18, pp. 1914-1915, 2013.

[24] M. Íñigo, A. Coello, G. Fernández-Rivas et al., "Evaluation of the SediMax automated microscopy sediment analyzer and the Sysmex UF-1000i flow cytometer as screening tools to rule out negative urinary tract infections," Clinica Chimica Acta, vol. 456, pp. 31-35, 2016.

[25] G. Gessoni, G. Saccani, S. Valverde, F. Manoni, and M. Caputo, "Does flow cytometry have a role in preliminary differentiation between urinary tract infections sustained by gram positive and gram negative bacteria? An Italian polycentric study," Clinica Chimica Acta, vol. 440, pp. 152-156, 2015.
[26] G. Martín-Gutiérrez, A. Porras-González, C. Martín-Pérez, J. A. Lepe, and J. Aznar, "Evaluation and optimization of the Sysmex UF1000i system for the screening of urinary tract infection in primary health care elderly patients," Enfermedades Infecciosas y Microbiologia Clinica, vol. 33, no. 5, pp. 320-323, 2015.

[27] F. Manoni, L. Fornasiero, M. Ercolin et al., "Cutoff values for bacteria and leukocytes for urine flow cytometer Sysmex UF1000 i in urinary tract infections," Diagnostic Microbiology and Infectious Disease, vol. 65, no. 2, pp. 103-107, 2009.

[28] M. Marschal, M. Wienke, S. Hoering, I. B. Autenrieth, and J.S. Frick, "Evaluation of 3 different rapid automated systems for diagnosis of urinary tract infections," Diagnostic Microbiology and Infectious Disease, vol. 72, no. 2, pp. 125-130, 2012.

[29] J. Gutiérrez-Fernández, A. Lara, M. Bautista et al., "Performance of the Sysmex UF1000i system in screening for significant bacteriuria before quantitative culture of aerobic/facultative fast-growth bacteria in a reference hospital," Journal of Applied Microbiology, vol. 113, no. 3, pp. 609-614, 2012.

[30] K. Kadkhoda, K. Manickam, P. DeGagne et al., "UF-1000i' ${ }^{\mathrm{TM}}$ flow cytometry is an effective screening method for urine specimens," Diagnostic Microbiology and Infectious Disease, vol. 69, no. 2, pp. 130-136, 2011.

[31] B. Pieretti, P. Brunati, B. Pini et al., "Diagnosis of bacteriuria and leukocyturia by automated flow cytometry compared with urine culture," Journal of Clinical Microbiology, vol. 48, no. 11, pp. 3990-3996, 2010.

[32] W. C. van der Zwet, J. Hessels, F. Canbolat, and M. M. L. Deckers, "Evaluation of the Sysmex UF-1000i ${ }^{\circledR}$ urine flow cytometer in the diagnostic work-up of suspected urinary tract infection in a Dutch general hospital," Clinical Chemistry and Laboratory Medicine, vol. 48, no. 12, pp. 1765-1771, 2010.

[33] R. De Rosa, S. Grosso, G. Bruschetta et al., "Evaluation of the Sysmex UF1000i flow cytometer for ruling out bacterial urinary tract infection," Clinica Chimica Acta, vol. 411, no. 1-16, pp. 1137$1142,2010$.

[34] Y. Shang, Q. Wang, J. Zhang et al., "Systematic review and metaanalysis of flow cytometry in urinary tract infection screening," Clinica Chimica Acta, vol. 424, pp. 90-95, 2013.

[35] X. Hu, J. Zhang, and X. Zhang, "Evaluation of the sysmex UF$1000 \mathrm{i}$ urine analyzer as a screening test to reduce the need for urine cultures for urinary tract infection," Laboratory Medicine, vol. 41, no. 6, pp. 349-352, 2010.

[36] T. Kouri, G. Fogazzi, V. Gant et al., "European urinalysis guidelines," Scandinavian Journal of Clinical and Laboratory Investigation, vol. 60, supplement 231, pp. 1-96, 2000.

[37] G. Schmiemann, E. Kniehl, K. Gebhardt, M. M. Matejczyk, and E. Hummers-Pradier, "The diagnosis of urinary tract infection. A systematic review," Deutsches Ärzteblatt International, vol. 107, no. 21, pp. 361-367, 2010.

[38] L. S. Garcia, Clinical Microbiology Procedures Handbook, American Society for Microbiology Press, 3rd edition, 2010.

[39] E. H. Kass, "Bacteriuria and pyelonephritis of pregnancy," A.M.A Archives of Internal Medicine, vol. 105, no. 2, pp. 194-198, 1960.

[40] Guidelines on Urological Infections, "European Association of Urology," http://www.uroweb.org/nc/professional-resources/ guidelines/online/.

[41] L. E. Nicolle, S. Bradley, R. Colgan, J. C. Rice, A. Schaeffer, and T. M. Hooton, "Infectious diseases society of America guidelines for the diagnosis and treatment of asymptomatic bacteriuria in adults," Clinical Infectious Diseases, vol. 40, no. 5, pp. 643-654, 2005. 
[42] T. M. File Jr., "Highlights from international clinical practice guidelines for the treatment of acute uncomplicated cystitis and pyelonephritis in women: A 2010 update by the infectious diseases society of America and the european society for microbiology and infectious diseases," Infectious Diseases in Clinical Practice, vol. 19, no. 4, pp. 282-283, 2011.

[43] J. R. Delanghe, T. T. Kouri, A. R. Huber et al., "The role of automated urine particle flow cytometry in clinical practice," Clinica Chimica Acta, vol. 301, no. 1-2, pp. 1-18, 2000.

[44] H. M. Davey, A. S. Kaprelyants, D. H. Weichart et al., Estimation of Microbial Viability Using Flow Cytometry. Current Protocols in Cytometry, vol. 11, New York Wiley, New York, NY, USA, 1999.

[45] B. Moshaver, F. de Boer, H. van Egmond-Kreileman, E. Kramer, C. Stegeman, and P. Groeneveld, "Fast and accurate prediction of positive and negative urine cultures by flow cytometry," $B M C$ Infectious Diseases, vol. 16, no. 1, article no. 211, 2016.

[46] E. Gieteling et al., "Accurate and fast diagnostic algorithm for febrile urinary tract infections in humans," The Netherlands Journal of Medicine, vol. 72, no. 7, pp. 356-362, 2014.

[47] Z. Zaman, S. Roggeman, and J. Verhaegen, "Unsatisfactory performance of flow cytometer UF-100 and urine strips in predicting outcome of urine cultures," Journal of Clinical Microbiology, vol. 39, no. 11, pp. 4169-4171, 2001.

[48] Y. K. Shine, J. K. Young, M. L. Sun et al., "Evaluation of the Sysmex UF-100 urine cell analyzer as a screening test to reduce the need for urine cultures for community-acquired urinary tract infection," American Journal of Clinical Pathology, vol. 128, no. 6, pp. 922-925, 2007.

[49] F. Manoni, S. Valverde, F. Antico, M. M. Salvadego, A. Giacomini, and G. Gessoni, "Field evaluation of a second-generation cytometer UF-100 in diagnosis of acute urinary tract infections in adult patients," Clinical Microbiology and Infection, vol. 8, no. 10, pp. 662-668, 2002.

[50] J. Krongvoraluk et al., "A flow cytometric urine analyzer for bacteria and white blood cell counts plus urine dispstick test for rapid screening of bacterial urinary tract infection," Asian Biomedicine, vol. 6, no. 4, pp. 601-608, 2012.

[51] N. Geerts, K. Boonen, A. Boer, and V. Scharnhorst, "Cut-off values to rule out urinary tract infection should be genderspecific," Clinica Chimica Acta, vol. 452, pp. 173-176, 2016.

[52] J. Wang, Y. Zhang, D. Xu, W. Shao, and Y. Lu, "Evaluation of the sysmex UF-1000i for the diagnosis of urinary tract infection," American Journal of Clinical Pathology, vol. 133, no. 4, pp. 577$582,2010$.

[53] H. Okada, T. Shirakawa, A. Gotoh et al., "Enumeration of bacterial cell numbers and detection of significant bacteriuria by use of a new flow cytometry-based device," Journal of Clinical Microbiology, vol. 44, no. 10, pp. 3596-3599, 2006.

[54] K. Yasuma, M. Nagao, Y. Matsumura et al., "[Evaluation of a UF1000 i screening method to identify the bacteriuria for cultures and susceptibility testing].," Rinsho byori. The Japanese journal of clinical pathology, vol. 60, no. 11, pp. 1070-1074, 2012.

[55] A. Ilki, R. Ayas, S. Ozsoy, and G. Soyletir, "Cost-effectiveness of a new system in ruling out negative urine cultures on the day of administration," European Journal of Clinical Microbiology and Infectious Diseases, pp. 1-5, 2017.

[56] G. Schmiemann, I. Gágyor, E. Hummers-Pradier, and J. Bleidorn, "Resistance profiles of urinary tract infections in general practice - An observational study," BMC Urology, vol. 12, article no. 33, 2012.

[57] J. M. Haslund, M. Rosborg Dinesen, A. B. Sternhagen Nielsen, C. Llor, and L. Bjerrum, "Different recommendations for empiric first-choice antibiotic treatment of uncomplicated urinary tract infections in Europe," Scandinavian Journal of Primary Health Care, vol. 31, no. 4, pp. 235-240, 2013.

[58] X.-H. Wang, G. Zhang, Y.-Y. Fan, X. Yang, W.-J. Sui, and X.-X. Lu, "Direct identification of bacteria causing urinary tract infections by combining matrix-assisted laser desorption ionization-time of flight mass spectrometry with UF-1000i urine flow cytometry," Journal of Microbiological Methods, vol. 92, no. 3, pp. 231-235, 2013.

[59] L. Ferreira, F. Sánchez-Juanes, J. L. Muñoz-Bellido, and J. M. González-Buitrago, "Rapid method for direct identification of bacteria in urine and blood culture samples by matrix-assisted laser desorption ionization time-of-flight mass spectrometry: Intact cell vs. extraction method," Clinical Microbiology and Infection, vol. 17, no. 7, pp. 1007-1012, 2011.

[60] M. Fritzenwanker, C. Imirzalioglu, T. Chakraborty, and F. M. Wagenlehner, "Modern diagnostic methods for urinary tract infections," Expert Review of Anti-Infective Therapy, vol. 14, no. 11, pp. 1047-1063, 2016. 

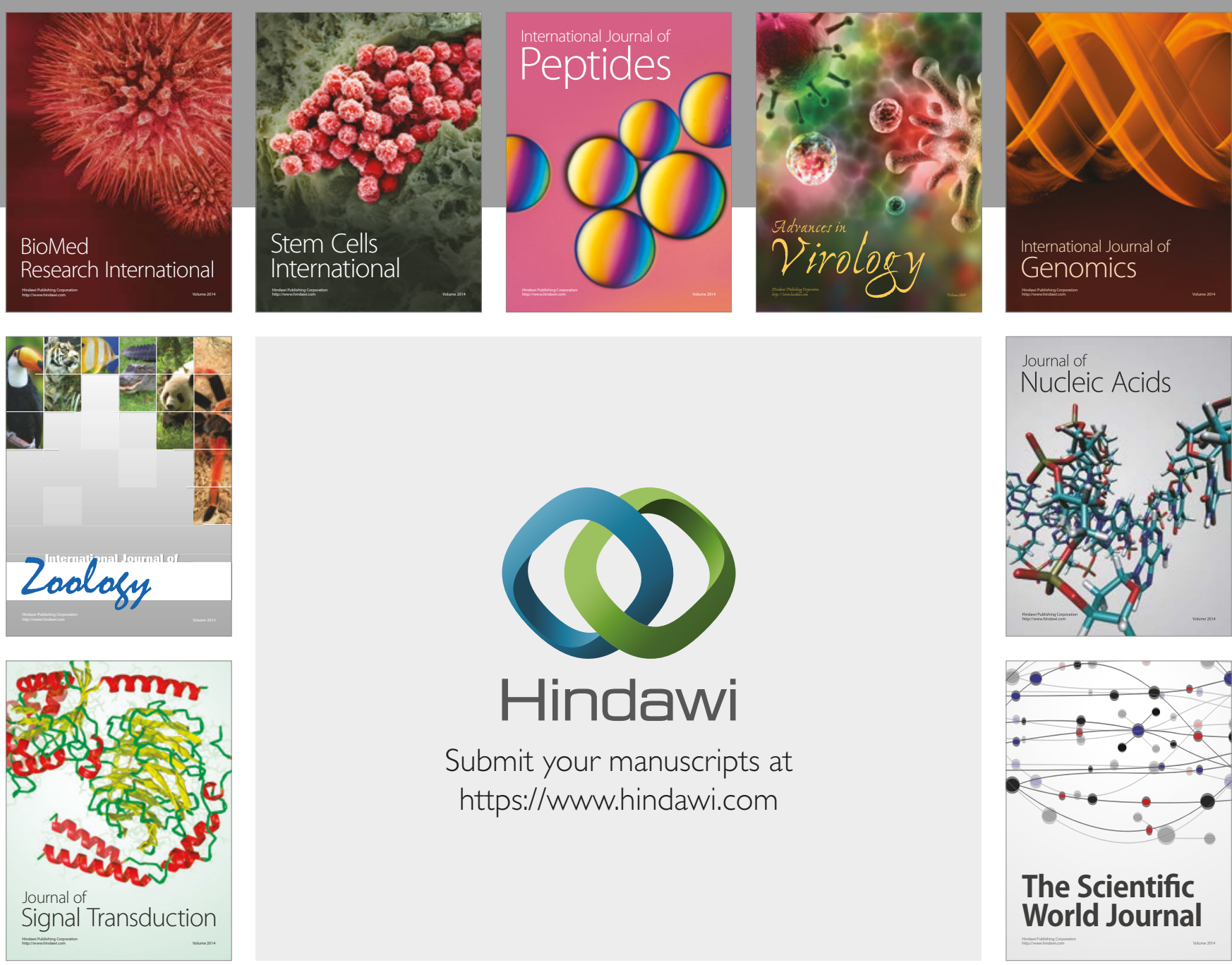

Submit your manuscripts at

https://www.hindawi.com
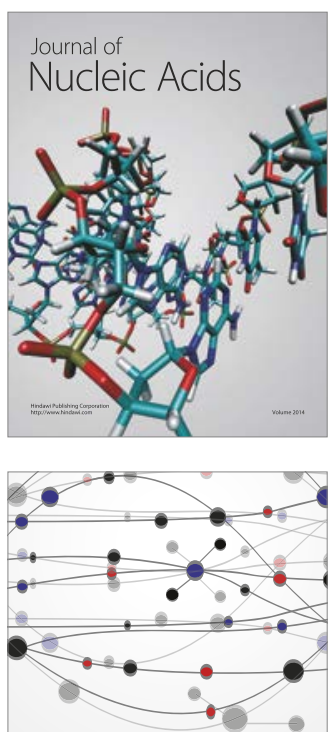

The Scientific World Journal

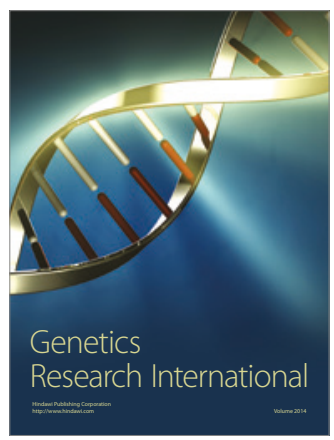

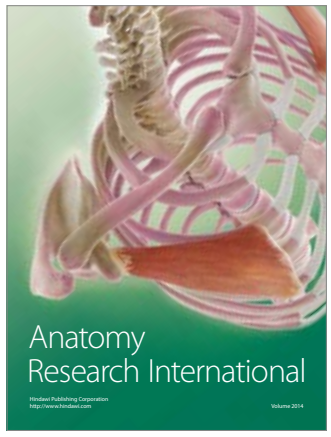

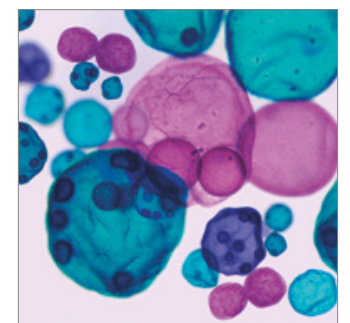

International Journal of Microbiology
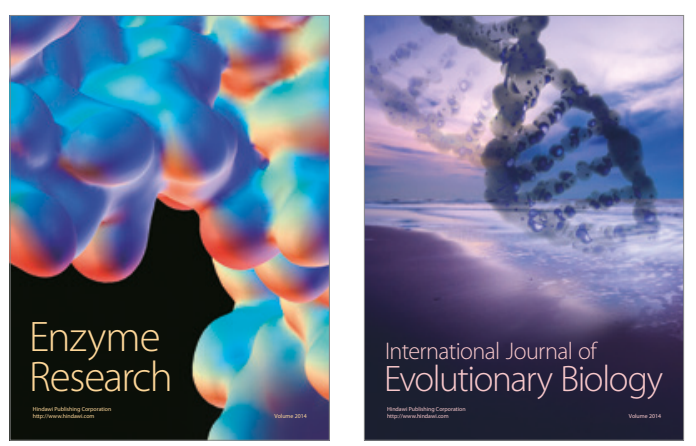
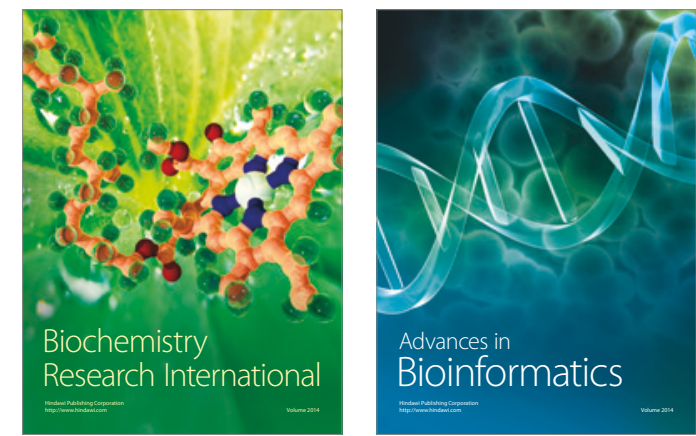

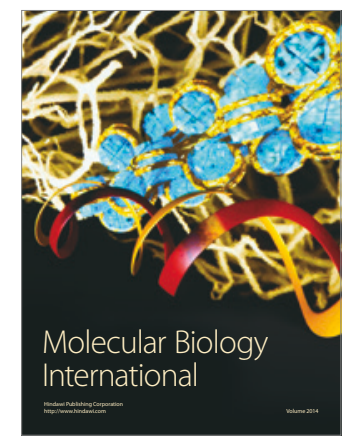

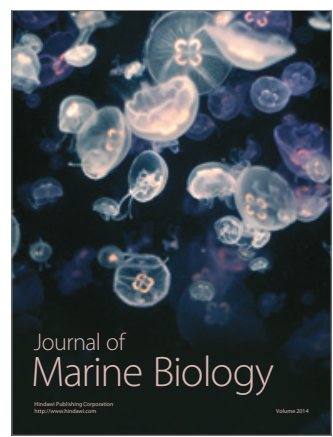

